\title{
A Declaração Universal sobre os Arquivos (DUA): uma reflexão de sua representação social
}

\author{
Jackson Guterres-dos Santos* \\ Jaires Oliveira-Santos ${ }^{\star \star}$ \\ Maria Isabel de Jesus Sousa-Barreira**
}

Artículo recibido:

4 de agosto de 2015

Artículo aceptado:

28 de octubre de 2016

\section{Resumen}

Este estudio tiene como objetivo elucidar la representatividad social de la Declaración Universal de los Archivos (DUA) en el ámbito de la inteligencia colectiva y de las habilidades requeridas en el proceso de aprendizaje y comprensión de los usuarios y del público en general. La Declaración establece un nuevo enfoque para la preservación del patrimonio documental y la protección de la memoria individual y colectiva, socializando la conciencia de la responsabilidad de todos en la salvaguarda del proceso de construcción del conocimiento. Este es un estudio descriptivo que utiliza un método de investigación bibliográfica y documental,

* Tribunal Regional do Trabalho, Brasil jackson@trt4.jus.br

** Universidade Federal da Bahia, Brasil jaires.oliveira@ufba.br isasousa@ufba.br

INVESTIGACIÓN BIBLIOTECOLÓGICA, vol. 32, núm. 75, abril/junio, 2018, México, ISSN: 2448-8321 pp. 163-181 
y realiza un análisis de la UDA, su historia e impacto en el proceso de construcción el compromiso de todos en la percepción de la importancia de la preservación de los archivos, las bibliotecas y los museos. La UDA colabora en el desarrollo de la concientización de los ciudadanos para la necesidad de formar profesionales en habilidades de información y convertirse en agentes de memoria y facilitadores del acceso a la información archivada. El estudio concluye con recomendaciones para inclusión de los temas de la UDA en los currículos de los cursos de Biblioteconomía y Archivística, asegurando así que sus principios sean comprendidos y experimentados en la práctica profesional, mientras que sirve para construir la identidad social y el conocimiento.

Palabras clave: DUA; Consciencia social; Preservación; Memoria

The Universal Declaration on Archives (UDA): one reflection about its social representative

Jackson Guterres-dos Santos, Jaires Oliveira-Santos and Maria Isabel de Jesus Sousa-Barreira

\section{Abstract}

This study aims to elucidate the social representativeness of the Universal Declaration on Archives (UDA) within the framework of collective intelligence and skills required in the learning process, and comprehension of users and the general public. The Declaration posits a new approach to the preservation of documentary heritage and protection of individual and collective memory, socializing awareness of the responsibility of everyone in safeguarding the process of knowledge construction. This is a descriptive study that employs a bibliographical and documentary research method, and undertakes an analysis of UDA, its history and impact on the process of building the engagement of all in the perception of the importance of preservation of archives in libraries and museums. UDA collaborates in the development of citizens' awareness of the need to train professionals in information skills and become agents of memory and facilitators of access to archived information. The study concludes with recommendations for additional UDA topics in Library and Archival 
Science curricula, thereby ensuring its principles are understood and experienced in professional practice, while serving to build social identity and knowledge.

Keywords: UDA; Social Awareness; Preservation; Memory

\section{INTRODUÇÃO}

Declaração Universal sobre os Arquivos (DUA) é cristalina ao demonsAtrar em seu escopo um protagonismo social e arquivístico expresso na forma como apresenta o valor da informação para a construção da cidadania. Nessa direção, o estudo pretende elucidar o que esse documento representa para a sociedade, no âmbito da inteligência coletiva e das competências requeridas no processo de aprendizagem e apreensão dos usuários e da opinião pública. A DUA declara a relevância da preservação do patrimônio documental, da memória e da necessidade de políticas e legislação de arquivos que garantam o direito de acesso à informação.

A iniciativa de uma pesquisa bibliográfica e documental da DUA justifica-se pelo fato da identificação de uma lacuna de estudos dessa natureza na literatura nacional. Ressalta-se que se trata de um documento recentemente adotado pela UNESCO, a partir da sua elaboração pelo Conselho Internacional de Arquivos (CIA), e, é considerada, pelo Arquivo Nacional (AN), como o primeiro documento oficial elaborado, em uma tradução bilateral, no português unificado, entre o AN e o Arquivo Nacional da Torre do Tombo de Portugal.

A DUA declara que a preservação documental e memorial, precisa ser compreendida como um compromisso de toda a sociedade, no garantir às gerações futuras, o acesso à informação, por meio de uma gestão democrática e transparente, priorizando o respeito aos direitos humanos e à cidadania. A DUA cumpre essa missão socializante da arquivística numa linguagem acessível.

O presente artigo evidenciara como a DUA alcança a consciência social dos cidadãos e da esfera pública mundial, colaborando no instruir os usuários, ou "clientes" - conforme alguns teóricos arquivistas - naqueles pontos fundamentais do que é a Arquivologia, da missão do Arquivista e do envolvimento da sociedade na questão da preservação documental e no processo coletivo de construção da memória social - individual e coletiva.

Para a consecução desse estudo investigou-se a origem da DUA e sua historicidade buscando ancora-la na referência de literatura e em autores que ajudassem a compreender o ambiente arquivístico global onde a DUA foi concebida e adotada como uma Declaração Universal. 
Partindo dessa assertiva, fomenta-se uma relação dialógica entre a Academia, estudantes, pesquisadores e profissionais da área da informação, cujo foco é a DUA e a competência em informação que propõe, a fim de instigar uma reflexão sobre o papel social das unidades informacionais e culturais, do profissional da informação, assim como, da importância do engajamento de todos na preservação do patrimônio documental e da memória, e, no difundir a premência do direito do livre acesso à informação.

A evidência da importância da DUA e de seu reconhecimento mundial, incluindo o Brasil, consiste na adoção dessa Declaração pela UNESCO enquanto documento oficial, que hoje encontra-se traduzida em 36 idiomas. Existem algumas versões no formato de poster colorido, tamanho A4, em PDF, nos idiomas das nações onde existe tradição arquivística, como Portugal e Brasil, disponíveis no site do Conselho Internacional de Arquivos (CIA) - International Council on Archives (ICA) - na web-página da DUA. Cita-se que há uma página no website do ICA onde todos - e não só os Arquivistas podem registrar seu apoio à DUA. ${ }^{1}$

A DUA orienta, portanto, a sociedade no processo do aprendizado e alfabetização informacional, colaborando não só para o desenvolvimento de habilidades e atitudes, mas também colabora para a autonomia do cidadão no buscar a informação e no direito de livre acesso o que tende a impactar na sua qualidade de vida, conforme preceitua a DUA, em seu preâmbulo.

\section{BREVE HISTÓRICO DA DUA}

A DUA é considerada pelo Conselho Internacional de Arquivos (CIA) um dos pilares fundamentais da sua política de defesa e foi, preliminarmente, aprovada em 2009 na sua Assembleia Anual realizada no arquipélago de Malta. Entretanto, a DUA, na sua versão definitiva no original em inglês, foi oficialmente adotada pelo, em 17 de setembro de 2010 na sua Assembleia Geral, realizada na cidade de Oslo. O CIA, ou ICA, é uma organização profissional da comunidade global de arquivos com 1.400 associados e representação em 190 países - segundo informação do sítio do Arquivo Nacional (Arquivo Nacional, 2016) - e está sediado em Paris.

Os delegados do ICA/SPA (Section for Professional Associations of ICA) Seção de Associações Profissionais (SAP) então reunidos decidiram aprovar o texto da declaração, por unanimidade. A DUA, ou Universal Declaration on 
Archives (UDA) foi inspirada na Declaração dos Arquivos de Quebec - 11 de janeiro de 2006, conforme explicitado:

desenvolvida pelo ICA/SPA [...] tomando como modelo a 'Déclaration québecoise des Archives', a declaração Universal de Arquivos (UDA), estabelece de forma concisa as características únicas de arquivos e os requisitos de gestão para fornecer acesso contínuo durante o tempo em que os registros forem necessários. Foi concebida como uma base à defesa e difusão do apoio aos arquivos e a profissão abrangendo um vasto público. (ICA, 2011, tradução nossa)

A DUA foi definitivamente adotada pela UNESCO e oficializada, em sua universalidade, na $36^{a}$ Assembleia Geral dessa entidade, que ocorreu em Paris, França, no dia dia 10 de novembro de 2011. Destaca-se que a declaração já havia sido aprovada na International Conference of the Round Table on Archives (CITRA), realizada em Oslo, em 17 de setembro de 2010.

Menciona-se também um evento arquivístivo global, o Congresso Internacional Arquivos sem Fronteiras - Archives Without Borders (AWB), que aconteceu no Palácio de Haia, de 30 a 31 de agosto de 2010 onde já se vislumbrava um clima favorável à DUA, como um texto consolidado e aprovado. Esse evento celebrava o centenário da primeira Conferência Arquivística Internacional, que aconteceu em Bruxelas, no ano de 1910. O texto da convocatória do evento nos permite contemplar os assuntos relevantes que dominavam a cena da arquivística global, em 2010:

Os arquivos sem fronteiras concentra sua atenção na importância de tem os arquivos para o bom funcionamento do governo no contexto internacional. Uma boa gestão de arquivos é uma condição obrigatória para a continuidade, eficácia e transparência dos serviços tanto públicos como privados, e a forma como se prestam contas. Em vários aspectos, a importância dos serviços transcendem as fronteiras, particularmente ante a perspectiva da globalização da sociedade da informação. (O evento dos) Arquivos sem Fronteiras oferecerá sessões relacionadas com os temas: 'Solidariedade Arquivística', 'Direitos Humano e Arquivos', 'Arquivos Transnacionais' e 'Arquivos na construção do Estado-Nação e da identidade nacional'. (ICA, 2010, tradução nossa)

A citação demonstra claramente a consonância entre as temáticas do congresso de AWB e o texto da DUA. Nesse contexto Cook (2012) já sugeria que, no olhar paradigmático da pós-modernidade, o papel da ciência arquivística devia voltar-se à interpretação social nos seguintes eixos: "memória, identidade e comunidade". Esta concepção há havia sido defendida anteriormente pelo Arquivista espanhol Fugueras (2003), nos eixos: "patrimônio, memória, identidade e conhecimento". 
A DUA logo após a sua aprovação teve, no Brasil, uma tradução preliminar extraoficial. Em fins de 2010, já havia uma sinalização de um pedido de tradução oficial para o Arquivo Nacional (AN) por um dos autores deste estudo que colaborou nesse processo enviando um e-mail à Claudia Lacombe, Diretora do Arquivo Nacional, enviando um esboço de tradução, a partir do texto da DUA em espanhol. A Diretora acenou positivamente para a sugestão, informando que o assunto foi encaminhado para uma das Câmaras Técnicas do AN.

Posteriormente, um acordo entre o Arquivo Nacional e o Arquivo Nacional da Torre do Tombo, em Portugal, resultou no texto da DUA, no português unificado, tendo sido o primeiro documento bilateral, oficialmente, celebrado entre Brasil-Portugal. O texto integral da DUA, em sua versão definitiva, pode ser encontrado no site do ICA, em vários idiomas, e, a versão oficial em português também encontra-se no site do Arquivo Nacional.

A DUA, por ser originalmente um documento representativo das aspirações globais de profissionais arquivistas foi produzida com inteligência coletiva e colaborativa, para fornecer informação acurada à opinião pública sobre a relevância dos arquivos e a importância de qualificação adequada de nível superior a todos os profissionais da informação, a fim de colaborarem no processo de formação da consciência social sobre a responsabilidade de todos no preservar os documentos arquivístico, na construção da memória e no garantir o direito de acesso.

Propõem-se que o mérito da DUA ao colaborar na difusão dos aspectos relacionados à preservação documental, bem como no processo de instruir a esfera pública acerca da relevância desses espaços de memória, esteja alinhado com o recurso da competência em informação. A missão profissional de instruir os usuários e a sociedade em geral, tem em si o requisito elementar da competência em informação, conforme corroborado por Miranda (2004: 118):

A competência informacional mobilizada em situações de trabalho pode ser vista como um dos requisitos do perfil profissional necessário para trabalhar com a informação, não importando o tipo de profissional ou de atividade [...] seria desejável que as competências informacionais fizessem parte do rol de competências dos mais variados profissionais, atividades e organizações.

A DUA agrega conhecimento fornecendo ideias e noções acerca da solidária co-responsabilização da sociedade, no que tange a preservação do patrimônio documental, da necessidade da construção da memória social, e do adequado tratamento documental, pela via da gestão arquivística, para que o cidadão possa exercer o seu direito de livre acesso à informação, no tempo que ele precisar. 
A adoção da DUA pela UNESCO, pode estar correlacionada com a implementação da Lei de Acesso à Informação (LAI) em muitos países, notadamente no Brasil, conforme matéria publicada no Observatório de Acesso à Informação Pública (OAIP), onde Soares (2012) sugere que a DUA “traz aos cidadãos noções básicas sobre arquivologia e a importância do tratamento e gestão documental, fundamentais para a implantação da Lei 12.527/11" Lei Federal que regulamenta o acesso à informação (LAI).

A organicidade da DUA, em conformidade com o apoio colaborativo das inteligências coletivas que lhe deram origem e o processo de competência em informação na elaboração de políticas de arquivos, pode ser ilustrada na Figura 1, elaborado a partir de estudos empreendidos durante a presente pesquisa:

\begin{tabular}{|c|c|c|}
\hline $\begin{array}{l}\text { Quebec, no Canadá, emite a } \\
\text { Declaração sobre Arquivos } \\
\text { de Quebec, em } 2006 \text { - data } \\
\text { da edição do arquivo da } \\
\text { declaração que consta no site } \\
\text { onde ela é disponibilizada. }\end{array}$ & $\begin{array}{l}\text { Atores sociais (profissionais da } \\
\text { informação) reunidos - } \\
\text { Arquivistas, Documentalista, } \\
\text { etc - elaboram uma } \\
\text { Declaração Universal sobre } \\
\text { Arquivos ( DUA). }\end{array}$ & $\begin{array}{l}\text { DUA nasce no seio da } \\
\text { SPA/ICA, foi aprovada em } \\
\text { setembro de } 2010 \text {. Com sua } \\
\text { aplicação e efeitos globais, é } \\
\text { adotada pela UNESCO, em } \\
\text { novembro de } 2011 \text {. }\end{array}$ \\
\hline $\begin{array}{l}\text { O Conselho Internacional de } \\
\text { Arquivos - CIA/ICA, } \\
\text { armazena e difunde a DUA, } \\
\text { reunindo suas } 36 \text { traduções } \\
\text { em uma página em seu } \\
\text { portal. Uma versão da DUA, } \\
\text { em português, tradução } \\
\text { binacional, Portugal e Brasil } \\
\text { é disponibilizada. Jun/2011 }\end{array}$ & $\begin{array}{l}\text { O Arquivo Nacional } \\
\text { protagonizou a versão da } \\
\text { DUA ao português, há uma } \\
\text { cópia da DUA no site do } \\
\text { AN. CIA cria uma página } \\
\text { para que todos registrem seu } \\
\text { apoio à DUA, a partir do } \\
\text { qual é gerado um escore dos } \\
\text { países apoiadores. }\end{array}$ & $\begin{array}{l}\text { A DUA precisa ser conhecida } \\
\text { amplamente; quanto mais } \\
\text { difundida tanto melhor. Cada um } \\
\text { pode fazer sua parte. Você já } \\
\text { registrou seu apoio a DUA? } \\
\text { E a difusão precisa continuar na } \\
\text { esfera da competência em } \\
\text { informação e alfabetização } \\
\text { informacional dos usuários. }\end{array}$ \\
\hline
\end{tabular}

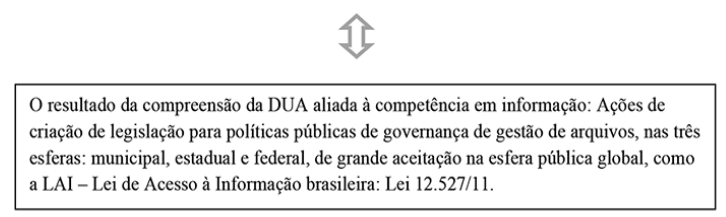

Figura 1. A Organicidade da DUA

Fuente: Elaborado pelos autores, com base na DUA (2010)

A partir dos pressupostos da DUA, infere-se que a gestão de arquivos seja realizada com competência em informação, o que engloba todos os atores e nos motiva a compreender que esse é um processo dinâmico, vivo que está em movimento no definir legislação e políticas públicas de gestão de arquivos, em todas as esferas de atividades sociais - públicas e privadas. 
$\mathrm{O}$ arquivista espanhol Ramon Alberch Fugueras, ao tratar da responsabilidade dos arquivistas no âmbito da informação, sugere que eles devem proporcionar "certa autonomia" aos usuários na medida do desempenho de seu papel social de mediadores. Sob esse prisma sugere-se uma correlação com a competência em informação o que parece evidente no que a DUA declara. Eis o que Fugueras (2003: 7-8) propõe: “[...] é indubitável que as três profissões com mais tradição no âmbito da informação - arquivistas, bibliotecários e documentalistas - deverão desempenhar um papel de 'mediação' para propiciar uma certa autonomia de nossos 'clientes' na busca da informação".

É essencial o processo de construção da autonomia dos usuários no atendimento as suas demandas informacionais. Os usuários têm sido renomeados por alguns arquivistas teóricos como "clientes", tal como Williams (2006) ao descrever sobre a política de acesso e serviços de reverência com base nos usuários: "Clientes internos estão igualmente usando recursos para fins corporativos, clientes externos para pesquisa”. A autonomia instrucional dos usuários ou clientes, proposta por Fugueras, pode ser compreendida como um constructo da competência em informação, que é corroborada a partir da praxis didática de Freire (2011: 47): “[...] o saber ensinar não é transferir conhecimento, mas criar as possibilidades para a sua própria produção ou sua construção". É possível estabelecer uma correlação entre essa autonomia instrucional dos usuários, ou clientes, com o chamamento coletivo da parte inicial da DUA, na expressão: "Por isso reconhecemos."

Conforme o presente estudo, os seis preceitos iniciais de reconhecimento público da DUA têm esse cunho didático de socialização da informação e clarificador de conceitos fundamentais da ciência arquivística frente aos usuários ou clientes e a sociedade. Esse fato pode ser evidenciado com a frase de efeito mobilizante, conscientizador e engajador: "Por isso reconbecemos", que encabeça os seis preceitos de compromissos coletivos. A frase está negritada, originalmente, na DUA, como grifo intencional dos próprios produtores do texto da declaração universal. Cabe mencionar que o verbete: "reconhecer", tem como significado, no dicionário Aurélio, dentre outros: "Ficar convencido de, admitir, ter como verdadeiro. Declarar legal, ter por legítimo” (Ferreira, 1999).

A DUA ao evocar o "Por isso reconhecemos", parece denotar que o verbo reconhecer está associado ao conhecer - obter conhecimento - e é justamente o que os seis preceitos deste reconhecimento público proporcionam, uma noção sucinta, competente e ampla do caráter dos arquivos, de sua diversidade, da multiplicidade de suportes e formatos, do papel essencial do arquivista 
e da responsabilidade solidária de todos na preservação do patrimônio documental, da memória e da missão social e cidadã dos arquivos no garantir os direitos humanos.

Vislumbra-se que a DUA é um instrumento importante que nasceu com a vocação de espraiar uma noção da práxis arquivística, colaborando para a educação dos usuários no senso da responsabilização coletiva, o que pode impactar na pressão social para que nossos legisladores priorizem a elaboração de legislações pertinentes que requeiram a implementação de políticas públicas de arquivos nas três esferas de governo. Eis os seis preceitos de reconhecimentos coletivos da DUA:

- o caráter singular dos arquivos como evidência autêntica das atividades administrativas, culturais e intelectuais e como um reflexo da evolução das sociedades;

- o caráter fundamental dos arquivos no apoio à condução eficiente, responsável e transparente de negócios, proteção dos direitos dos cidadãos, fundamentação da memória individual e coletiva, compreensão do passado, documentação do presente e orientação das ações futuras;

- a diversidade dos arquivos ao registrarem todas as áreas da atividade humana;

- a multiplicidade de suportes e formatos em que os documentos são produzidos, incluindo papel, audiovisual, digital e outros;

- o papel dos arquivistas, profissionais qualificados, com formação apropriada e contínua, que servem às suas sociedades, apoiando a produção, seleção e conservação dos documentos, e os tornam disponíveis para uso;

- a responsabilidade de todos, cidadãos, gestores e autoridades públicas, proprietários ou detentores de arquivos públicos ou privados, arquivistas e outros profissionais do campo da informação, na gestão de arquivos. (DUA, 2010)

À luz da tridimensionalidade integrante nos conceitos de Conhecimento, Habilidades e Atitudes (CHA) da competência - no âmbito conceitual da administração - o conhecimento dos seis itens elencados na DUA e supracitados, espelha o cerne da arquivologia, ao oferecer pontos chaves no discernimento do caráter singular dos arquivos, como evidências de atividades intelectuais, culturais e administrativas que habilitam os usuários a obterem a noção dos porquês os arquivos refletem a evolução da sociedade ou comunidade. 
O educador arquivístico Terry Eastwood observou que:

[...] é preciso entender o meio político, econômico, social e cultural de uma dada sociedade para compreender os seus arquivos, acrescentando que as ideias tidas sobre os arquivos, em qualquer dado momento, certamente nada mais são do que um reflexo de correntes mais amplas na história intelectual. (Eastwood, 1993: 27; Cook, 2012)

A citação acima reforça a tese da representação social como reconfiguração do cerne da ciência arquivística pós-moderna e correlaciona-se com o texto da DUA, no sentido que ela é um espelho da sociedade atual onde está implícita a necessidade de assimilar os aspectos estruturantes da sociedade para compreender os seus arquivos.

Ao arquivista é interessante ter consciência destes novos olhares, que estão direcionados a uma perspectiva social dos arquivos, que estes são considerados reflexos da história e intelectualidade de determinada sociedade. Imagina-se em uma comunidade indígena como seria desafiador desenvolver um projeto de arquivos e resgate da memória, uma vez que, em sua maioria, a tradição das tribos é de memória oral e pouco, ou quase nada, de documento impresso é produzido nessas comunidades. Eis um ponto que poderia ser explorado, no campo da pesquisa acadêmica.

A seguir analisa-se a DUA sob o prisma da sociedade atual e o modus operandi arquivístico que ela assinala nos seus seis preceitos de comprometimento e realce do papel social do arquivista. Os dois primeiros reconhecimentos da DUA revelam o caráter singular dos arquivos como reflexo da evolução das sociedades, e, o caráter fundamental dos arquivos no apoio à condução eficiente, responsável e transparente de gestão. Eles explicam a relevância dos arquivos como suporte à tomada de decisão, na transparência das negociações, na proteção dos direitos cidadãos e no fundamentar a memória individual e coletiva.

A DUA no seu primeiro item de reconhecimento coletivo, ao mencionar a relação orgânica do documento com o registro das atividades humanas, elucida uma noção elementar do que deva ser considerado documento de arquivo, noção fundamental diante de certa incompreensão existente na opinião pública, não só local, como na "esfera pública" global - termo cunhado por Lemos e Lévy (2010) para reconfigurar o clássico conceito de "opinião pública" à luz do ciberespaço e da ciberdemocracia. Essa dimensão do caráter singular dos arquivos como evidência, e porque não dizer espelhamento, de todas as atividades administrativas, culturais e intelectuais reflete a evolução social. 
O próprio estigma equivocado de "arquivo morto" proporciona aos arquivistas o desafio de desconstruir essa falácia sobre os Arquivos para que, pela via da competência em informação, possam atuar, no instruir o público usuário com informação acurada. Nesse ponto, a DUA vem declarar a relevância de se reconhecer a diversidade dos arquivos, porque eles registram a atividade humana, em todas as áreas do conhecimento.

A evolução dos suportes e formatos dos documentos está contemplada no quarto item que retrata a atual multiplicidade de suportes: o suporte papel, audiovisual, digital e outros. Até pouco tempo a quase totalidade das atividades registrais orgânicas - resultante das atividades administrativas, culturais e intelectuais - eram registradas unicamente em papel. Atualmente a realidade é outra, pois a virtualidade está mudando essa prática, do suporte físico para o meio digital e eletrônico, retratando o modo como as pessoas estão se comunicando, com a utilização de equipamentos decorrentes das evoluções tecnológicos, emergindo daí o processo eletrônico.

Prosseguindo nessa análise, percebe-se algo bem útil em termos de alfabetização informacional dos usuários, em consonância com a competência em informação, considerando que com a multiplicidade de suportes e formatos, demanda dos usuários competências e habilidades para o uso de tais equipamentos. No terceiro milênio, essa pluralidade parece desafiando a arquivística para um constante apropriar-se de requisitos técnicos e científicos, no sentido da correta preservação e recuperação de dados. As atividades informacionais estão sendo armazenadas em suportes tecnologicamente sofisticados como os discos óticos, DVDs, e, em ambientes virtuais emergentes(nuvem), toda essa virtualidade dos suportes implica no desafio coletivo da preservação digital.

Neste contexto, uma situação prática que surge à gestão de arquivos, qual seja a preservação da informação, no novo paradigma do processo eletrônico que inclui a garantia da integridade dos dados, o uso de metadados e modelos de requisitos, bem como a segurança da informação - mantendo o sistema livre de pragas virtuais, como vírus e outros softwares maliciosos.

Por outro lado deve haver a constante lembrança que existe uma parcela da população que ainda não tem acesso à Internet, cujo analfabetismo digital precisa ser levado em consideração e minimizado. Entretanto, enquanto isso não acontece, caberá aos profissionais da informação e as instituições, garantirem o livre acesso através da manutenção de espaços públicos - quiosques onde o serviço de acesso aberto aos cidadãos deve ser disponibilizado através de equipe destinada a atuar como mediadores da informação. Essa prática, já vem sendo utilizada em tribunais regionais federais que adotaram o sistema de processo eletrônico. 
O papel do arquivista é o quinto item de reconhecimento. Nele está descrito, sucintamente, o fazer arquivístico, enquanto metodologia consagrada no trato documental e imprescindível para a gestão de arquivos e a gestão da informação. Ressalta ainda, a necessidade do arquivista ter formação de categoria superior, adequada a alto posto de responsabilidade social que a profissão requer. O item finaliza com a missão precípua do arquivista de tornar os documentos disponíveis para acesso e uso, seja para as finalidades de gestão, democrática e transparente, seja como fontes históricas, a partir do momento em que os documentos, passam a assumir a fase de servir à construção do processo histórico e da memória social - individual e institucional. Nesse caminho, o texto ressalta a relevância da formação apropriada e continuada, bem como o fazer alinhado com sua competência em informação apoiando a produção, seleção e conservação documental, promovendo competências que possibilitem o acesso livre, respeitando a legislação arquivística vigente e a Lei de Acesso à Informação.

O último item de compromisso coletivo da DUA realça a responsabilidade solidária de todos, fazendo uma convocatória aos principais atores sociais imprescindíveis a esse chamamento explícito na DUA (2010): "cidadão, gestores, autoridades públicas, proprietários ou detentores de arquivos públicos ou privados, arquivistas e outros profissionais do campo da informação, na gestão de arquivos." Percebe-se, que todos os envolvidos são convidados a ser protagonistas e incentivadores da elaboração de políticas de arquivos, pois sem elas, os arquivos estariam condenados à pecha de "arquivos mortos", ao invés de ter a viva realidade de uma unidade de informação fundamental à cidadania e ao processo de construção da identidade social, do conhecimento, da memória e da garantia dos direitos humanos, em especial o direito de acesso à informação.

\section{A DUA E OS SEIS COMPROMETIMENTOS DE TRABALHAR JUNTOS}

Do que está declarado no texto da DUA e sob a ótica da competência em informação, os profissionais da informação, a governança e a esfera pública podem compreender que os arquivos são essenciais para a solidez democrática, o sucesso e a transparência de gestão, o respeito aos direitos dos cidadãos e para preservar o patrimônio documental, a memória e identidade da sociedade. A DUA projeta uma luz sobre essas questões fundamentais à organização social, conclamando a todos para uma tomada de consciência em relação ao compromisso social de cada um: 
Por isso nos comprometemos a trabalhar juntos, para que

- sejam adotadas e aplicadas nacionalmente políticas e legislação arquivística adequadas;

- a gestão de arquivos seja valorizada e realizada com competência por todos os organismos, públicos ou privados, que produzem e usam documentos de arquivo na condução de seus negócios;

- sejam disponibilizados os recursos necessários para apoiar a adequada gestão dos arquivos, inclusive a contratação de profissionais capacitados;

- os arquivos sejam geridos e conservados de forma a garantir a sua autenticidade, confiabilidade, integridade e uso;

- os arquivos sejam acessíveis a todos, respeitando a legislação pertinente e os direitos dos indivíduos, produtores, proprietários e usuários;

- os arquivos sejam utilizados de modo a contribuir para a promoção de uma cidadania responsável. (DUA, 2010)

A DUA declara como preceito primordial a adoção e aplicação de políticas e legislação arquivística adequadas, considerado que ambas são recursos democráticos indispensáveis na coesão social e basilar na manutenção do estado de direito, para todos indistintamente. Em face disso, por que não incluir, solidaria e colaborativamente todos para atuarem juntos primordialmente para fomentar legislação e políticas públicas de arquivo, em todas as três esferas da administração pública: federal, estadual e municipal?

O segundo item de comprometimento menciona a gestão de arquivos a ser implementada com competência pelas instituições de qualquer natureza responsáveis pela produção e uso das informações nas atividades desempenhadas. Aqui podemos extrapolar o sentido estrito do termo competência, para abarcar sua tridimensionalidade: conhecimento, habilidade e atitude, sob a vertente da transdisciplinaridade que expande os horizontes conceituais e propõe novos olhares, a fim de melhor dialogar com os diversos atores que atuam nesse compromisso solidário proclamado pela DUA (2010) "Por isso nos comprometemos a trabalhar juntos".

O item seguinte expresso na DUA, toca na questão premente da disponibilização dos recursos necessários para melhor gerir a informação arquivística. Nesse contexto, é realçado que investimentos (materiais e humanos) são imprescindíveis ao atendimento dos objetivos propostos na presente declaração. Há que se observar nessa questão que o documento enfatiza a contratação de profissionais capacitados, na qual exige-se formação superior.

Embora que, em momentos de crise econômica, os recursos financeiros escasseiam, por outro lado, na proporção em que a sociedade une-se contra a 
corrupção, a expectativa é que haja melhor aproveitamento dos recursos públicos, oriundos de impostos, e nada mais justo que retornem aos cidadãos naquilo que pode beneficia-lo, diretamente, nesse sentido, o apoio às unidades informacionais e culturais do país deveria ser prioridade.

Quanto mais se investe na gestão de arquivos, melhor a gestão da informação, no âmbito empresarial, o que lhes assegura um diferencial na competitividade, haja vista que a informação e o conhecimento são o cerne das tomadas de decisões e na excelência de atendimento aos clientes, e, uma gestão competente impacta na competitividade.

No quarto item de comprometimento está a essência da preservação, o qual constitue-se em preceitos da ciência arquivística, amplamente reconhecidos no meio profissional, que também aplicam-se na preservação de documentos eletrônicos ou digitais. Hoje, essa exigência de garantir a preservação da informação - autenticidade, confiabilidade, integridade - notadamente no meio digital, tem sido objeto de pesquisa, como o projeto INTERpares (coordenado pela Universidade de British Columbia (UBC), Canadá), Luciana Duranti, professora doutora canadense da UBC.

O requisito da preservação anteriormente mencionado, portanto, passa pela meta primordial de garantir a segurança da informação e o direito de livre acesso, ou seja, o que tende a viabilizar sua acessibilidade e seu uso consagrado à pertença cidadã dos arquivos não só no presente, mas também no longo prazo.

Na sequência, a DUA trata do objetivo e razão das unidades informacionais e culturais existirem, ou seja, que as instituições arquivística garantam o acesso à informação da coletividade em geral, respeitando os preceitos legais. Esse item alude a dois princípios da arquivística: o princípio da proveniência e o princípio da territorialidade. Além disso, atende ao preceito ético do direito de acesso e respeito à legislação arquivística, onde todos são contemplados: coletividade, produtores de documentos, os proprietários de documentos e/ou coleções que doam seus acervos e os usuários, bem como pesquisadores em geral.

No sexto item de comprometimento, a DUA evoca a essência de uma arquivística social e socializante, cuja finalidade é colaborar na construção de uma sociedade mais justa e iqualitária, ao estabelecer o uso dos arquivos para promover uma cidadania responsável e plena, sua identidade e memória social. Concebe-se esse item como sintetizador do inteiro teor da DUA o qual está alinhado-se ao que está expresso no preâmbulo DUA (2010): "Arquivos são fontes confiáveis de informação para ações administrativas responsáveis e transparentes. (...) ao contribuir para a constituição e salvaguarda da memória individual e coletiva”. E o item conclui com um resumo sucinto da 
DUA ao declarar que os arquivos sejam utilizados para contribuir com "a promoção de uma cidadania responsável”, correlaciona-se com a frase final do preâmbulo, ao mencionar que o livre acesso enriquece o conhecimento, a democracia protegendo os direitos dos cidadãos, tudo isto "aumenta a qualidade de vida”.

O exposto nesse estudo do texto da DUA, revelou a importância das instituições arquivística bem como o "poder dos arquivos", expressão cunhada pelo arquivista americano Jimerson (2008), ${ }^{2}$ onde ele sugere os três aspectos essenciais dessa potencialidade, explicados na metáfora comparativa do templo, da prisão e do restaurante:

Ao invés de esconder o nosso poder no reino da memória, da história e do passado, espero que os arquivistas abracem o poder dos arquivos e usem-no para o bem da humanidade. Antes de analisarmos as respostas a este desafio de usar o poder dos arquivos, precisamos entender algumas de suas manifestações. Há três aspectos essenciais do poder dos arquivos, refletidos nas metáforas abaixo. - O TEMPLO: autoridade e controle sobre a memória (coletiva) social; - A PRISÃO: o controle sobre a preservação e segurança dos documentos de arquivos; - O RESTAURANTE: o papel do arquivista como intérprete e mediador entre os documentos e os usuários.

O exercício do nosso papel como atores sociais, na função pontífice de interpretes e mediadores entre a informação documental e os usuários, - leva a efeito as predições da competência em informação, com conhecimento e habilidade traduzidos em atitudes engajadas, como a de divulgar a relevância da DUA para a sociedade como um todo.

Em termos de um instrumento de apoio à competência em informação, é desejável que a DUA seja difundida na academia, que faça parte da grade curricular dos cursos de arquivologia e biblioteconomia, para que possa ganhar mais visibilidade nas instituições, seja na publicidade digital, seja imprimindo-a e mantendo-a em algum lugar visível a todos os usuários. $\mathrm{O}$ conhecimento desse documento de efeito universal, que socializa a arquivologia, tende a colaborar no processo de construção da consciência social e profissional em relação à importância da preservação, da gestão de arquivos, da relevância das unidades informacionais no direito de acesso à informação, no processo de resgate da memória, bem como no viabilizar a governabilidade democrática e promoção da cidadania responsável no rumo da qualidade de vida.

2 Durante muitos anos, Randall C. Jimerson foi Diretor-Presidente da Society American of Archivist (SAA), é Professor de História e Diretor do Programa de Graduação em Arquivos da Universidade de Washington, EUA. 


\section{Considerações Finais}

A DUA declara o caráter fundamental e multifacetado dos arquivos, na gestão de negócios das organizações, na proteção dos direitos cidadãos e no processo de "fundamentação da memória individual e coletiva, compreensão do passado, documentação do presente e orientação para ações futuras" (DUA, 2010).

A DUA é uma declaração que nasceu no Terceiro Milênio, como um documento originalmente digital, que organicamente registrou os anseios dos arquivistas reunidos em uma associação, cientes do desafio de informar à sociedade que a preservação patrimonial e memorial é crucial para a interpretação social, para garantia dos direitos humanos que passa pelo direito de livre acesso à informação pública e cidadã.

A competência em informação, conforme sugere o termo information literacy, surgiu como um modo de alavancar a educação do público usuário, como elemento primordial para minimizar o analfabetismo informacional e o analfabetismo digital promovendo a autonomia na busca de atender suas demandas em informação. Como resultado de nossa análise concebe-se que a DUA tem um papel colaborativo na instrução do público em relação à informação arquivística e a construção da memória.

A organicidade da DUA, portanto, foi a de registrar as aspirações dos arquivistas e demais profissionais da Ciência da informação, no sentido de que haja reconhecimento público do papel desses profissionais, da relevância das unidades informacionais, e da necessidade de que é imprescindível trabalhar juntos, colaborativamente na preservação do patrimônio documental, base para a construção da memória social.

A DUA, por sua simplicidade, pela fluidez de sua linguagem que preteriu a terminologia arquivística para comunicar, com uma linguagem acessível capaz de tocar o coração dos cidadãos e conclamar a sociedade, na esfera global, para compreender que preservar e definir políticas públicas de arquivos, em todas as esferas é uma questão de governança e gestão eficiente, democrática e transparente.

A salvaguarda da memória, da identidade e do conhecimento para assegurar direitos e o registro das atividades humanas em cada localidade é um imperativo social que se auto-impõe à consciência social, solidária e colaborativa em linha com o princípio arquivístico da territorialidade.

Infere-se que a DUA é um documento de finalidade ímpar associado a qualquer declaração do porte de uma declaração universal. Pela força e competência de seu texto e a luz da transdisciplinaridade, infere-se que a DUA expressa pressupostos inerentes à competência em informação, pois ela aponta 
caminhos e tem um aporte instrucional e clarificador em seu conteúdo.

Para maior amplitude de acesso ao conteúdo da DUA, sugere-se que esta seja disponibilizada nos sites da área da informação, arquivologia, biblioteconomia, blogs e redes sociais, aproveitando os recursos da autocomunicação - comunicação pessoa-pessoa ou mass self communication, predita por Castells (2006). Por fim, sugere-se disponibilizar uma cópia impressa da DUA em locais visíveis ao público nas unidades informacionais, notadamente nos Arquivos públicos e privados, haja vista que a DUA, assessorada pela competência em informação, nela implícita, socializa o respeito ao patrimônio documental e a memoria como fundamentais ao processo de construção da identidade e conhecimento.

Nesse cenário, a DUA é um documento que ajudará também na educação das novas gerações para conscientização da importância dos arquivos e da relevância dos profissionais da ciência da informação, que são os mediadores entre as casas de memória e os cidadãos.

\section{REFERÊNCIAS}

Arquivo Nacional. 2016. "Ações Internacionais". Conselho Internacional de Arquivos - CIA. 17 jan. 2018. Acesso em: 26 abr. 2018. http://www.arquivonacional. gov.br/br/acoes-internacionais/85-conselho-internacional-de-arquivos-cia.html

Brasil. Lei de Acesso à Informação. Lei No 12.527, 18 de novembro de 2011: Regula o acesso a informações. Acesso em: 27 mai. 2015. http://www.planalto.gov.br/ccivil_03/_ato2011-2014/2011/lei/112527.htm

Castells, Manuel. 2006. "A Era da Intercomunicação”. Le Monde Diplomatique Brasil. Acesso em: 02 jun. 2015. http://www.diplomatique.org.br/acervo.php?id=1915

Cook, Terry. 2012. "A ciência arquivística e o pós-modernismo: novas formulações para conceitos antigos". InCID: Revista de Ciência da Informação e Documentação 3 (Ribeirão Preto) (jul./dez.) (2): 3-27. Acesso em: 20 maio 2015. www.revistas. usp.br/incid/article/download/48651/52722

Cook, Terry. 2001. "Archival science and postmodernism: new formulations for old concepts". Journal Archival Science 1 (1): 3-24.

DUA (Declaração Universal sobre os Arquivos). 2010. Acesso em: 27 mai. 2015. http://www.ica.org/13343/universal-declaration-on-archives/universal-declaration-on-archives.html

Eastwood, Terence M. 1993. "Reflections on the development of archives in Canada and Australia", en Archival documents: providing accountability through recordkeeping, Sue McKemmish y Frank Upward (ed.), 27-39. Melbourne: Ancora Press.

Ferreira, Aurélio Buarque de Holanda. 1999. Dicionário Aurélio Básico da Língua Portuguesa. Rio de Janeiro: Nova Fronteira.

Freire, Paulo. 2011. Pedagogia da autonomia: saberes necessários à prática educativa, 43. ed. São Paulo: Paz e Terra. 
Fugueras, Ramon Alberch. 2000. Ampliación del Uso Social de los Archivos. Estrategias y Perspectivas. Palestra no Seminário Internacional de Arquivos de Tradição Ibérica. 3-7 abr. 2000. Anais. Rio de Janeiro: Conarq. v. 1, p. 1 - 16. Acesso em: 23 mai. 2015. http://www.conarq.arquivonacional.gov.br/Media/publicacoes/ibericas/ampliaci n_del_uso_social_de_los_archivos.pdf

Fugueras, Ramon Alberch. 2003. Los Archivos, entre la memoria histórica y la sociedad del conocimiento. Barcelona: Editorial U.

ICA (International Council on Archives). 2011. The Universal Declaration on Archives adopted by the Annual General Meeting in Oslo. Acesso em: 20 mai.2015. http://www.ica.org/1055/news-events/the-universal-declaration-on-archives-adopted-by-the-annual-general-meeting-in-oslo.html

ICA. 2010. Archives Without Borders Internacional Congress. Haia, International congress about the importance of archives for buman rights, good governance, formation of the nation state and national identity.

Jimerson, Randall C. 2008. XV Congresso Brasileiro de Arquivologia. Archives for All: the Importance of Archives in Society. http://www.aag.org.br/anaisxvcba/conteudo/resumos/plenaria1/randalljimerson.pdf

Lemos, André e Pierre Lévy. 2010. O futuro da internet: em direção a uma ciberdemocracia planetária. São Paulo: Paulus.

Miranda, Silvania Vieira. 2004. "Identificando competências informacionais". Ciência da Informação (Brasília) (maio/ago.) 33 (2): 112-122. Acesso em: 25 mai. 2015. http://www.brapci.inf.br/_repositorio/2010/02/pdf_9422f0c8f8_0008165.pdf

Projeto INTERPARES 3 - International Research on Permanent Authentic Records in Electronic Systems. Acesso em: 24 mai. 2015. http://www.interpares.org/ip3/ ip3_index.cfm?team $=4$

Seminário Internacional de Arquivos de Tradição Ibérica. 2000. Rio de Janeiro. Acesso em: 30 mai. 2015. http://www.conarq.arquivonacional.gov.br/cgi/cgilua.exe/sys/ start.htm? sid $=74$

Soares, Bruno. 2012. Declaração Universal sobre os Arquivos, a importância do tratamento e gestão documental, fundamentais para a implantação da Lei 12.527/11. Acesso em: 6 jun. 2015. http://informacaopublica.com.br/2012/05/13/declaracao-universal-sobre-os-arquivos-a-importancia-do-tratamento-e-gestao-documental-fundamentais-para-a-implantacao-da-lei-12-52711/

Williams, Caroline. 2006. Managing Archives: Foundations, Principles and Practice. Oxford: Chandos Publishing. 
Para citar este texto:

Guterres dos Santos, Jackson, Jaires Oliveira-Santos y Maria Isabel de Jesus Sousa-Barreira. 2018. "A Declaração Universal sobre os Arquivos (DUA): uma reflexão de sua representação social”. Investigación Bibliotecológica: archivonomía, bibliotecología e información 32 (75): 163-181.

http://dx.doi.org/10.22201/iibi.24488321xe.2018.75.57966 